Zoo Biology 21:37-47 (2002)

\title{
Intact Carcasses as Enrichment for Large Felids: Effects on On- and Off-Exhibit Behaviors
}

\author{
M. Elsbeth McPhee* \\ School of Natural Resources and Environment, University of Michigan, Ann Arbor, \\ Michigan
}

Reducing stereotypic behaviors in captive animals is a goal for zoological institutions worldwide, and environmental enrichment is one tool commonly used to meet that end. Behavioral needs associated with feeding, however, are often neglected in large carnivores. To address these needs, I tested the effects of calf carcasses as enrichment for large felids. Over 14 weeks, I provided nine animals with up to seven intact carcasses. The cats were housed at Toledo Zoo, Potawatomi Zoo, and Binder Park Zoo. Animals were observed off and on exhibit for changes in feeding, natural, stereotypic, active, and inactive behaviors. I compared treatment behaviors with behaviors observed during a baseline period in which the animals were fed traditional processed diets. For these nine cats, carcass provision decreased off-exhibit stereotypic behaviors but had little impact on on-exhibit behaviors. Zoo Biol 21:37-47, 2002. (c) 2002 Wiley-Liss, Inc.

Key words: feeding behavior; stereotypic behavior; carnivores

\section{INTRODUCTION}

Over evolutionary time, the behaviors of wild animals have taken shape in response to spatial and temporal variability and the selective pressures associated with that variability. Captivity can adversely affect animal behavior due to different selective pressures and a lack of environmental stochasticity [Hediger, 1964; Price, 1984; Tudge, 1992; Carlstead, 1996; Seidensticker and Forthman, 1998]. In a captive environment, an animal may not have the motivation, opportunity, or need to display the range of behaviors necessary to succeed in its natural habitat.

Large carnivores in particular are often deprived of natural behavioral opportunities associated with feedings. Captive felids in North American zoos are fed pri-

*Correspondence to: M. Elsbeth McPhee, 1209 Wells, Ann Arbor, MI 48104.

E-mail: mmcphee@umich.edu

Received for publication June 1, 2000; Accepted October 15, 2001. 
marily a diet of processed meat that offers few behavioral opportunities and takes moments to consume [Fernandes, 1996; Carlstead, 1998; Lindburg, 1998]. Continuous feeding of such a diet has physiological and behavioral consequences. For example, Duckler [1998] found that, as compared to those of wild individuals, the principal muscles operating the jaws and neck of captive-reared tigers (Panthera tigris) had a greatly reduced influence on the shape of the skull during development. This change is likely due to excessive grooming and lack of appropriate feeding opportunities [Duckler, 1998]. Studies have also shown that animals fed whole-prey items vs. those fed processed meat suffered fewer gingival health problems, less plaque formation, and less focal palatine erosion [Lindburg, 1988].

In addition, prolonged exposure to an environment without appropriate external stimuli or selective pressures can elicit aberrant, stereotypic behaviors, which are possibly 1) redirections of behaviors (especially appetitive behaviors) with no natural outlet in captivity, or 2) mechanisms to cope with the lack of stimulation [Mason, 1993; Rushen et al., 1993; Carlstead, 1996]. Aberrant behaviors such as pacing, head swinging, and excessive licking are commonly described in a number of mammalian carnivore species (e.g., polar bear (Ursus maritimus) [Markowitz, 1982; Tudge, 1991], tiger (Panthera tigris) [Markowitz, 1982; Tudge, 1991], leopard (Panthera pardus) [Markowitz, 1995], caracal (Felis caracal) [Hancocks, 1980; Hutchins et al., 1984], and ocelot (Felis pardalis) [Hutchins et al., 1984]). An environment that offers appropriate stimuli for eliciting wild behavior is likely to reduce the probability of such behavioral changes [Hancocks, 1980; Frankham et al., 1986; Maple and Finlay, 1989; Tudge, 1992; Newberry, 1995; Carlstead, 1996].

The use of environmental enrichment provides animals with a variety of valuable stimuli [e.g., see The Shape of Enrichment]. Enrichment decisions, however, are often based on item availability and cost, not the animals' behavioral ecology. Here I propose that whole-prey items be tested as enrichment for large carnivores. Studies have shown that: 1) the method of food provision and the level of stereotypic behaviors are linked in carnivores [Carlstead, 1998; Mellen et al., 1998], and 2) provision of whole prey directly addresses the animals' behavioral ecology [Bond and Lindburg, 1990].

\section{METHODS}

To test this approach, I asked the following questions: Does the behavior of captive cats change significantly with the provision of intact carcasses? Specifically, does the mean number of samples in which the animal displayed natural vs. stereotypic, and active vs. inactive behaviors change over time? Of special interest was the change in stereotypic behaviors.

To answer these questions, I observed behavior under two scenarios: 1) off exhibit - the behaviors observed off exhibit for the first $2 \mathrm{hr}$ immediately following provision of intact calf carcasses, and 2) on exhibit-behavior observed on exhibit throughout the 2 weeks between carcass provisions.

Against a null hypothesis that behavior would not change after carcass provision, I predicted that off-exhibit, stereotypies would decrease and that natural and feeding behaviors would increase. For behavior on exhibit, I predicted that stereotypic and active behaviors would decrease after carcass provision, and that natural and inactive behaviors would increase. 


\section{Subjects/Carcasses}

Not all cats received the same number of carcasses, nor were all cats involved in both parts of the study. Nine cats were fed carcasses, and eight cats were observed on exhibit. Cats were housed at Potawatomi Zoo (PZ), South Bend, Indiana; Toledo Zoo (TZ), Toledo, Ohio; and Binder Park Zoo (BPZ), Battle Creek, Michigan. All cats were born in captivity and had received intact carcasses (though not calf) at some point in their life (Table 1).

For both portions of the study, animals were observed and behaviors were clearly defined prior to the official data-collection period. Definitions were based on work by Curio [1976], Leyhausen [1979], Taylor [1989], Bailey [1993], and Mason [1993] (Table 2).

\section{Protocol}

\section{Behavior off exhibit}

The protocol for behavior off exhibit is separated into two sections: 1) provision (carcass procurement, preparation, and provision), and 2) data collection (how the data were collected).

\section{Provision}

Each treatment animal received one carcass per 2-week cycle. For each of the zoos, carcasses were purchased from local farmers. At the request of participating veterinarians, carcass preparation included evisceration.

Four days prior to provision, carcasses were removed from the freezer and placed in a refrigerator to thaw. The morning of provision, the carcasses were set out to reach room temperature. Carcasses were weighed and then provided to the animals between 1630 and $1700 \mathrm{hr}$ on scheduled days.

\section{Data Collection}

To record feeding behavior, I placed a videocamera on a tripod, and recording began immediately prior to provision. Behaviors were recorded for a 2 -hr period.

Before the first carcass provision, baseline data were taken on cats feeding on their regular diet (PZ and BPZ: Nebraska ${ }^{\circledR}$ feline diet (Central Nebraska Packing, Inc., North

TABLE 1. Demographic information for each subject*

\begin{tabular}{|c|c|c|c|c|c|c|}
\hline Cat & Zoo & Species & Sex & Age & $\begin{array}{c}\text { Years at } \\
\text { institution }\end{array}$ & $\begin{array}{l}\text { Hand raised/ } \\
\text { mother reared }\end{array}$ \\
\hline $\mathrm{L} 1_{\mathrm{p} 7}$ & $\mathrm{PZ}$ & African leopard & 0.1 & 19 & 19 (all) & HR \\
\hline $\mathrm{L} 33_{\mathrm{p} 2}$ & $\mathrm{PZ}$ & African leopard & 0.1 & 22 & 22 (all) & HR \\
\hline $\mathrm{L} 12_{\mathrm{t} 7}$ & $\mathrm{TZ}$ & African leopard & 1.0 & 21 & $10+$ & Unknown \\
\hline $\mathrm{N} 2_{\mathrm{p} 5}$ & $\mathrm{PZ}$ & Lion & 1.0 & 7 & 2 & HR \\
\hline $\mathrm{N}_{\mathrm{p}} 3_{\mathrm{t} 5}$ & $\mathrm{TZ}$ & African lion & 0.1 & 13 & $10+$ & Unknown \\
\hline $\mathrm{S} 7_{\mathrm{b} 2}$ & $\mathrm{BPZ}$ & Snow leopard & 0.1 & 9 & 1 & MR \\
\hline $\mathrm{S} 8_{\mathrm{b} 2}$ & BPZ & Snow leopard & 1.0 & 11 & 1 & MR \\
\hline$S 9_{t 7}$ & $\mathrm{TZ}$ & Snow leopard & 0.1 & 6 & 6 (all) & MR \\
\hline$S 10_{t 7}$ & $\mathrm{TZ}$ & Snow leopard & 0.1 & 6 & 6 (all) & MR \\
\hline
\end{tabular}

*To designate subjects, uppercase letter = species; uppercase number = unique identification number; subscript letter $=$ zoo; and subscript number $=$ number of carcasses fed (uppercase letters: $\mathrm{L}=$ leopard, $\mathrm{N}=$ lion, and $\mathrm{S}=$ snow leopard; subscript letters: $\mathrm{p}=$ Potawatomi Zoo, $\mathrm{b}=$ Binder Park Zoo, and $\mathrm{t}=$ Toledo Zoo). 
TABLE 2. Behavioral definitions and categories in which each behavior was considered*

\begin{tabular}{|c|c|c|c|c|c|c|}
\hline Behavior & Definition & $\mathrm{F}$ & $\mathrm{N}$ & $\mathrm{S}$ & $\mathrm{A}$ & $\mathrm{I}$ \\
\hline Walk & $\begin{array}{l}\text { Ambulatory movement in a specific direction with an } \\
\text { apparent goal; a symmetrical gait in which each foot is } \\
\text { on the ground more than half the time [Taylor 1989] }\end{array}$ & & $\mathrm{X}$ & & $\mathrm{X}$ & \\
\hline Pace & $\begin{array}{l}\text { Repeated walking, without an apparent goal [Mason 1993]; } \\
\text { walking became pacing as soon as the animal completed } \\
\text { two rotations of the movement pattern }\end{array}$ & & & $\mathrm{X}$ & $\mathrm{X}$ & \\
\hline Jump & $\begin{array}{l}\text { Moving from a lower point to a higher point, or vice versa, } \\
\text { in one motion }\end{array}$ & & $\mathrm{X}$ & & $\mathrm{X}$ & \\
\hline Drag & $\begin{array}{l}\text { Move a portion of an item, with the mouth beside or } \\
\text { between the cat's front legs, from one location to } \\
\text { another without lifting it off the floor [Leyhausen 1979] }\end{array}$ & $\mathrm{X}$ & $\mathrm{X}$ & & $\mathrm{X}$ & \\
\hline Stalk & $\begin{array}{l}\text { Slow, walking movement, with all legs slightly bent, and } \\
\text { eyes focused on specific item }\end{array}$ & $\mathrm{X}$ & $\mathrm{X}$ & & $\mathrm{X}$ & \\
\hline Lick & Stroke object with tongue & $\mathrm{X}$ & $\mathrm{X}$ & & & $\mathrm{X}$ \\
\hline Bite & Placing the mouth around an item and exerting force & $\mathrm{X}$ & $\mathrm{X}$ & & $\mathrm{X}$ & \\
\hline Chew & Grind an object, usually with the carnassials & $\mathrm{X}$ & $\mathrm{X}$ & & & $\mathrm{X}$ \\
\hline Carry & $\begin{array}{l}\text { Pick an item (or portion thereof) off of the floor and move } \\
\text { from one location to another }\end{array}$ & & $\mathrm{X}$ & & $\mathrm{X}$ & \\
\hline Stretch & $\begin{array}{l}\text { (a) Hind legs straight out behind the body, front legs } \\
\text { straight but still under the body }\end{array}$ & & $\mathrm{X}$ & & & $\mathrm{X}$ \\
\hline & $\begin{array}{l}\text { (b) Front legs straight out in front of body, back legs } \\
\text { straight but still under the body }\end{array}$ & & & & & \\
\hline At rest & Relaxed, calm; in a sitting position & & $\mathrm{X}$ & & & $\mathrm{X}$ \\
\hline Vigilant & Alert, attentive; either standing or sitting & & $\mathrm{X}$ & & & $\mathrm{X}$ \\
\hline Maintenance & Eating, drinking, urinating, grooming & & $\mathrm{X}$ & & & \\
\hline Plucking & $\begin{array}{l}\text { Excessive grooming; focuses on a specific spot, versus } \\
\text { area, and continues for several minutes oftening } \\
\text { resulting in visible loss of hair at that spot }\end{array}$ & & & $\mathrm{X}$ & & $\mathrm{X}$ \\
\hline Other & Any behavior that did not fit any of the above categories & $\mathrm{X}$ & $\mathrm{X}$ & $\mathrm{X}$ & $\mathrm{X}$ & $\mathrm{X}$ \\
\hline
\end{tabular}

${ }^{*} \mathrm{~F}$ = feeding; $\mathrm{N}=$ natural $\mathrm{S}$ = stereotypic; $\mathrm{A}=$ active $; \mathrm{I}=$ inactive.

Platte, NE); TZ: Nebraska ${ }^{\circledR}$ canine diet (Central Nebraska Packing, Inc.)). For baseline and treatment data, behaviors were noted in 12 instantaneous scan samples [Altmann, 1974] per hour taken at 5-min intervals, totaling 24 samples per subject per night.

\section{Behavior on exhibit}

To examine behavior on exhibit, data were collected four times a day on specified days. Each day was divided into four 1-hr 15-min rounds: 1000-1115, 1145$1300,1,330-1445$, and $1515-1630 \mathrm{hr}$. I determined exhibit order within a round with a random number generator. Per each round, one 10-min observation was made of each exhibit, and each 10-min observation consisted of 10 instantaneous scan samples [Altmann, 1974] to be collected on the minute. Again, prior to the first carcass provision, data were taken on the cats on their routine diet of processed meat. These data served as the baseline against which behaviors with carcasses were compared. The treatment schedule was staggered to allow observations throughout the 2-week cycle.

\section{Analysis}

To address behavioral change as a function of intact carcass provision in the off-exhibit and on-exhibit studies, I looked at overall change for all cats pooled, as well as for individual cats. Because the data were ultimately analyzed as count data 
(i.e., comparing numbers of scans observed), I used Poisson regression [P] [SAS Software Release 6.12] to determine the significance of change for groups of pooled cats. Because not all cats received the same number of carcasses, I compared treatment to baseline on three different levels of analysis: 1) cats that received carcasses 1 and 2 pooled $(n=6) ; 2)$ cats that received carcasses $1-5$ pooled $(n=5)$; and 3$)$ cats that received carcasses $1-6$ pooled $(n=3)$ (Table 3$)$.

Given the small sample size and strong dependence among observations, I analyzed change for individual cats using a bootstrapped two-sample independent t-test [B] [Bradley and Tibshirani, 1993]. The lack of variance and the small sample size rendered traditional statistical methods inappropriate for individual cats. The bootstrap is a repeated sampling technique that compensates for these problems. Using SAS [SAS Software Release 6.12], I programmed a computer to resample the data 1,000 times for each cat. Based on these trials, SAS calculated a probability that the sample means were different. This test assumed equal variances, and there were few serious departures from homogeneity (using the Brown-Forsythe test for homogeneity). However, $12 \%$ of the cases did violate the assumption, which indicates that the results should be interpreted with moderate confidence. Because the baseline data for cats $\mathrm{S} 7_{\mathrm{b} 2}, \mathrm{~S} 8_{\mathrm{b} 2}$, and $\mathrm{S} 9_{\mathrm{t} 7}$ were incomplete or missing, I substituted $\mathrm{S} 10_{\mathrm{t}}$ 's baseline data ( $\mathrm{S} 10_{\mathfrak{t} 7}$ was the only conspecific). There is no confirmation that the cats' behaviors were similar enough to warrant the substitution, so these results should be interpreted with caution. I compared all statistical results against an $\alpha=0.05$.

\section{RESULTS}

\section{Behavior Off Exhibit}

\section{Feed behaviors}

Do big cats exhibit more feeding activity with a carcass than with processed diet? At first this seems to be an uninteresting question, with an obvious answer: of course they do. However, this study found that while overall increases were significant, not all cats responded with increased feeding activity.

Overall, there was a significant increase in feeding behaviors at all three levels of analysis (level $1[\mathrm{P}] P=.0045$; level 2, [P] $P=.0002$; level 3, [P] $P<.0001$; Table 4). On an individual basis, one cat $\left(\mathrm{L}_{\mathrm{p} 2}\right)$ experienced a significant overall decrease in feeding behaviors $([\mathrm{B}] P=.027)$ and only three cats $\left(\mathrm{L} 1_{\mathrm{p} 7}, \mathrm{~L} 12_{\mathrm{t} 7}\right.$, and $\mathrm{N} 13_{\mathrm{t} 5}$ ) experienced a significant overall increase ([B] $P=.008, .0001$, and .0001 , respectively; Table 5).

TABLE 3. Levels of analysis

\begin{tabular}{lll}
\hline Analysis level & $\mathrm{n}$ \\
\hline Off-exhibit behavior & & \\
1 & Carcasses 1 and 2 pooled & 6 \\
2 & Carcasses 1 through 5 pooled & 5 \\
3 & Carcasses 1 through 6 pooled & 3 \\
On-exhibit behavior & & \\
1 & Carcasses 1 and 2 pooled & 8 \\
2 & Carcasses 1 through 5 pooled & 5 \\
3 & Carcasses 1 through 7 pooled & 4 \\
\hline
\end{tabular}


TABLE 4. Significance values for overall change in behaviors for all cats pooled (for levels of analysis, see Table 3)

\begin{tabular}{|c|c|c|c|c|}
\hline Treatment & Behavior & $\begin{array}{c}\text { Level of } \\
\text { analysis }\end{array}$ & P value* & $\begin{array}{l}\text { Direction of change } \\
\text { (if significant) }\end{array}$ \\
\hline \multirow[t]{9}{*}{ Off exhibit } & Feed & 1 & .0045 & + \\
\hline & & 2 & .0002 & + \\
\hline & & 3 & $<.0001$ & + \\
\hline & Natural & 1 & .1353 & $t^{\mathrm{a}}$ \\
\hline & & 2 & .3798 & $t^{a}$ \\
\hline & & 3 & .2576 & $t^{\mathrm{a}}$ \\
\hline & Stereotypic & 1 & .3160 & $-{ }^{\mathrm{a}}$ \\
\hline & & 2 & .0968 & $-{ }^{\mathrm{a}}$ \\
\hline & & 3 & .0822 & $-{ }^{\mathrm{a}}$ \\
\hline \multirow[t]{15}{*}{ On exhibit } & Natural & 1 & .3021 & \\
\hline & & 2 & .6435 & \\
\hline & & 3 & .5355 & \\
\hline & Stereotypic & 1 & .8205 & \\
\hline & & 2 & .5132 & \\
\hline & & 3 & .5551 & \\
\hline & Inactive & 1 & .7104 & \\
\hline & & 2 & .8305 & \\
\hline & & 3 & .8858 & \\
\hline & Active & 1 & .4934 & \\
\hline & & 2 & .1025 & \\
\hline & & 3 & .1401 & \\
\hline & Hiding & 1 & .0470 & + \\
\hline & & 2 & .0053 & + \\
\hline & & 3 & .0087 & + \\
\hline
\end{tabular}

*P values based on Poisson regression and compared to an $\alpha$ of .05.

${ }^{a}$ Poisson regression is not significant, but comparison of proportions indicates change did occur.

\section{Natural vs. stereotypic behaviors}

The first question asked by managers of enrichment programs is usually, Does the enrichment decrease stereotypic behavior? Initially, it appears that carcass provision produces no significant overall change in either natural or stereotypic behaviors for animals off exhibit (Table 4).

A factor that potentially masks significance for natural and stereotypic behaviors, however, is hiding behaviors (periods in which the focal animal retreated from the observer's view). Given that, I also considered proportionate data to normalize for time out of sight. This normalization showed that, for all cats pooled, the percentage of samples in which natural behaviors were observed significantly increased at all three levels. For level 1, natural behaviors increased from $72 \%$ at baseline to $92 \%$ for all carcasses pooled. At level 2, the increase was from $66 \%$ to $95 \%$, and level 3 increased from $62 \%$ to $97 \%$.

Patterns for individual cats were more varied (Table 5). Only one cat $\left(\mathrm{L} 1_{\mathrm{p} 7}\right)$ experienced an overall increase in natural ([B] $P=.0001)$ and decrease in stereotypic behaviors ([B] $P=.0001)$. Natural behaviors also increased for $\mathrm{N}_{13}{ }_{\mathrm{t} 5}([\mathrm{~B}] P=$ $.0002)$ and $\mathrm{S} 8_{\mathrm{b} 2}([\mathrm{~B}] P=.021)$, and $\mathrm{L} 3_{\mathrm{p} 2}$ experienced an overall decrease in stereotypies ([B] $P=.021)$. 


\section{Carcass Enrichment}

TABLE 5. Significance values for behavior change in individual cats pooled (for definition of coding see Table 1)

\begin{tabular}{|c|c|c|c|c|}
\hline Treatment & Behavior & Cat & $\mathrm{P}$ value* & Direction of change \\
\hline \multirow[t]{11}{*}{ Off exhibit } & \multirow[t]{4}{*}{ Feed } & $\mathrm{L} 3_{\mathrm{p} 2}$ & .0270 & - \\
\hline & & $\mathrm{L} 1_{\mathrm{p} 7}$ & .0080 & + \\
\hline & & $\mathrm{L} 12_{\mathrm{t} 7}$ & .0001 & + \\
\hline & & $\mathrm{N} 13_{\mathrm{t} 5}$ & .0001 & + \\
\hline & \multirow[t]{3}{*}{ Natural } & $\mathrm{L} 1_{\mathrm{p} 7}$ & .0001 & + \\
\hline & & $\mathrm{S} 8_{\mathrm{b} 2}$ & .0210 & + \\
\hline & & $\mathrm{N} 13_{\mathrm{t} 5}$ & .0001 & + \\
\hline & \multirow[t]{2}{*}{ Stereotypic } & $\mathrm{L} 1_{\mathrm{p} 7}$ & .0001 & - \\
\hline & & $\mathrm{L} 3_{\mathrm{p} 2}$ & .0210 & - \\
\hline & \multirow[t]{2}{*}{ Hiding } & $\mathrm{S} 8_{\mathrm{b} 2}$ & .0210 & + \\
\hline & & $\mathrm{N} 13_{\mathrm{t} 5}$ & .0001 & - \\
\hline \multirow[t]{10}{*}{ On exhibit } & \multirow[t]{3}{*}{ Natural } & $\mathrm{L} 1_{\mathrm{p} 7}$ & .0010 & + \\
\hline & & $\mathrm{S} 10_{\mathrm{t} 7}$ & .0210 & - \\
\hline & & $\mathrm{N} 13_{\mathrm{t} 5}$ & .0001 & + \\
\hline & \multirow[t]{2}{*}{ Stereotypic } & $\mathrm{L} 1_{\mathrm{p} 7}$ & .0007 & - \\
\hline & & $\mathrm{S} 10_{\mathrm{t} 7}$ & .0130 & - \\
\hline & \multirow[t]{2}{*}{ Active } & $\mathrm{L} 1_{\mathrm{p} 7}$ & .0050 & - \\
\hline & & $\mathrm{S} 10_{\mathrm{t} 7}$ & .0080 & - \\
\hline & \multirow[t]{2}{*}{ Inactive } & $\mathrm{L} 1_{\mathrm{p} 7}$ & .0030 & + \\
\hline & & $\mathrm{S} 10_{\mathrm{t} 7}$ & .0440 & - \\
\hline & Hiding & $\mathrm{S} 10_{\mathrm{t} 7}$ & .0040 & + \\
\hline
\end{tabular}

*P values based on bootstrapped two-sample independent $t$-test and compared to an $\alpha$ of .05.

\section{Behavior On Exhibit}

Natural vs. stereotypic behaviors

Due to anticipated public reaction and perception, enrichment's effect on onexhibit stereotypic behaviors is generally of greater concern than that of behaviors off exhibit. As a function of carcass provision, there was no significant overall change in natural or stereotypic behaviors on exhibit at any level (Table 4). Again, the effect of hiding behaviors must be considered. Even normalizing for time out of sight, there was no change in time spent in active and stereotypic behavior.

Individually, overall natural behaviors significantly increased ([B] $P=.001)$ and stereotypic behaviors significantly decreased $\left([\mathrm{B}] P=.007\right.$ ) for cat $\mathrm{L} 1_{\mathrm{p} 7}$. For $\mathrm{S} 10_{\mathrm{t} 7}$, natural behaviors and stereotypies decreased when overall change was considered ([B] $P=.021$ and .013 , respectively) (Table 5).

\section{Inactive vs. active behaviors}

For big cats, inactivity is naturally the predominant state. At no level was there a significant overall change in inactive or active behaviors (Table 4).

For cat $\mathrm{L} 1_{\mathrm{p} 7}$, overall active behaviors significantly decreased ([B], $P=.005$ ) and inactives increased ([B], $P=.003)$, whereas cat $\mathrm{S} 0_{\mathrm{t} 7}$ experienced a significant overall decrease in active and inactive behaviors ([B], $P=.008$ and $P=0.44$, respectively) (Table 5).

\section{Hiding}

Animal visibility is an issue of concern for curators and managers of public institutions. Overall, there was a significant increase in hiding on exhibit at all three 
levels of carcass provision (level 1, [P], $P=.047$; level 2, [P], $P=.0053$; level 3, [P], $P=.0087$; Table 4).

\section{DISCUSSION}

\section{Behavior Off Exhibit}

Overall, the provision of carcasses had a positive effect on behavior off exhibit. For cats on baseline diet $\left(\right.$ Nebraska $\left.^{\circledR}\right)$, feeding behaviors comprised $5 \%$ or less of the 2-hr time period immediately following diet provision. With the provision of a carcass, that proportion increased to as much as $52 \%$ (for level $3, \mathrm{n}=3$ ).

In addition to positive changes in feeding behavior, carcasses also caused an increase in natural behaviors and a decrease in stereotypic behaviors for animals in the off-exhibit area. Although the changes were not statistically significant, change could have been masked by hiding behaviors. Considering the proportion of natural to stereotypic behaviors, however, natural behaviors increased and stereotypies decreased.

Not all cats observed in the off-exhibit study reacted as predicted to carcass provision. Some animals experienced sporadic change, no change at all, or changes in directions opposite from those predicted. One cat $\left(\mathrm{L}_{\mathrm{p} 2}\right)$ actually experienced a decrease in feeding behaviors, although other associative behaviors, such as guarding, increased. In fact, a Siberian tiger (Panthera tigris altaica) at Potawatomi Zoo was removed from the study after two carcasses because he appeared to experience extreme stress when a carcass was present. Toledo Zoo's snow leopards $\left(\mathrm{S}^{10} \mathrm{t}_{\mathrm{t}}\right.$ and $\mathrm{S} 9_{\mathrm{t} 7}$ ) consistently dragged and stashed carcasses out of the camera's view, and probable feeding activity was not recorded. Therefore, potentially significant changes were masked due to the method of data collection and analysis. The question then becomes, Why did certain cats respond and others did not? For the few cats involved in this study, there is no clear answer. Response to carcass provision, however, was not a function of institution, species, sex, age, or temperature. A larger sample size could provide more insight into this question.

\section{Behavior On Exhibit}

The provision of carcasses had little impact on behaviors on exhibit. There was no overall change in natural, stereotypic, active, or inactive behaviors, but hiding did increase in conjunction with carcass enrichment. Whether or not this increase is in fact due to carcass provision remains to be seen. More work is necessary to explore that relationship adequately.

In this study, carcass provision was not an effective deterrent to on-exhibit stereotypic behavior. More change might have been visible in the on-exhibit study if the subjects had displayed more stereotypies in their daily activity budgets. These cats were generally behaviorally healthy, which made positive change unlikely. For better understanding of on-exhibit behavioral changes as a function of carcass provision, studies should be conducted with more cats with well-defined aberrant behavioral patterns.

\section{Implications}

Large carnivores are evolutionarily adapted to capture, and consume large vertebrate prey [Curio, 1976; Leyhausen, 1979; Sunquist and Sunquist, 1989; Taylor, 
1989; Van Valkenburgh, 1989; Caro and Fitzgibbon, 1992; Alexander, 1993; Bailey, 1993; Seidensticker and McDougal, 1993; Biknevicius and Van Valkenburgh, 1996]. Currently, however, environmental enrichment programs for captive mammalian carnivores are not often based on the animals' behavioral ecology. Instead, they are based on item availability and ease of provision. Given this, I proposed that the provision of whole-prey items be tested as enrichment for large carnivores.

The present study has myriad limitations: multiple species, institutions, and data collectors; small sample size; and cats that showed extreme variability in behavior, ranging from immediate and complete consumption to extreme disinterest, bordering on fear. Despite all of these complications, the results strongly indicate that carcass provision has a positive impact on behaviors off exhibit-carcass provision decreases the number of stereotypic behaviors that occur off exhibit. However, the study did not find that whole-prey provision consistently decreased on-exhibit aberrant activity in captive carnivores, probably because of problems associated with the research being conducted at multiple institutions and on a small number of cats.

There have been few formal studies of this kind. Bond and Lindburg [1990] examined feeding behavior in cheetahs and demonstrated that cats fed carcasses spent more time feeding, exploring, and processing than those fed processed diets. Despite the primary role feeding plays in a carnivore's behavioral repertoire, however, carcass provision is not usually considered due to cost, labor, and potential public outcry.

A great deal of work is still needed for an understanding of how to accommodate the behavioral needs associated with feeding in large carnivores. Without a template or model, this research has laid the foundation for future work in this area. Mason [1993] indicated that stereotypic behaviors are species-typical, thus suggesting that reactions to enrichment could be species-typical as well. Given this, I suggest a study of at least 20 conspecifics with documented aberrant tendencies. This would provide solid, basic information on the effects of carcass provision on aberrant behaviors. Beyond that, an even larger sample size would be needed to explore the relationship of age and sex to carcass enrichment. No matter what the sample size, I suggest collecting more baseline data for the off-exhibit study and modifying either the enclosures or equipment to maximize the observer's ability to view individuals.

Even though carcass provision did not curtail aberrant behaviors on exhibit, it strongly enriched the animals' holding area. The effects of carcass provision did not persist over multiple days, so provisions should occur as often as each institution's budget and diet regime allow. Overall, carcass provision is an important enrichment technique that directly addresses the animals' behavioral ecology, morphology, and natural history.

\section{CONCLUSIONS}

1. For cats housed at Potawatomi Zoo, Toledo Zoo, and Binder Park Zoo, carcass provision decreased the number of stereotypic behaviors observed off exhibit.

2. Carcass provision did not consistently decrease stereotypic behaviors observed on exhibit in these captive carnivores, probably due to problems associated with the research being conducted at multiple institutions and on a small number of cats.

3. Carcass provision elicited an overall increase in feeding behaviors. 


\section{ACKNOWLEDGMENTS}

This work is the result of a massive collaborative effort. First, I thank the staffs of the Binder Park, Potawatomi, and Toledo Zoo, who were patient and willing to move objects and animals for this project. Specifically, I thank Tim French, Tim Reichard, Tom Benner, Beverly Schoonover, Jon Behnfeldt, Steve Krueger, John Dinon, Chuck Garland, Jenny Barnett, Curtis Eng, John Jaffee, and Betsy Court for their assistance with logistics and implementation. I also recognize Brian Young for hours of data collecting, study design advice, and troubleshooting; Nicole Mahler and Gayle Byker were instrumental in the data-collection efforts. Finally, I thank Chris Howes, James Malcolm, and an anonymous reviewer for their extremely helpful comments on the manuscript.

\section{REFERENCES}

Alexander RM. 1993. Legs and locomotion of Carnivora. Symp Zool Soc Lond 65:1-13.

Altmann J. 1974. Observational study of behaviour: sampling methods. Behaviour 49 227-67.

Bailey TN. 1993. The African leopard: ecology and behavior of a solitary felid. New York: Columbia University Press. 429 p.

Biknevicius AR, Van Valkenburgh B. 1996. Design for killing: craniodental adaptations of predators. In: Gittleman JL, editor. Carnivore behavior, ecology, and evolution. Vol. II. Ithaca, NY: Cornell University Press. p 393-428.

Bond JC, Lindburg DG. 1990. Carcass feeding of captive cheetahs (Acinonyx jubatus): the effects of a naturalistic feeding program on oral health and psychological well-being. Appl Anim Behav Sci 26:373-82

Bradley E, Tibshirani RJ. 1993. An introduction to the bootstrap. Monographs on statistics and applied probability, No. 37. New York: Chapman and Hall. 436 p.

Carlstead K. 1996. Effects of captivity on the behavior of wild animals. In: Kleiman D, Allen M, Thompson K, Lumpkin S, editors. Wild mammals in captivity. Chicago: University of Chicago Press. p 317-33.

Carlstead K. 1998. Determining the causes of stereotypic behaviors in zoo carnivores: toward appropriate enrichment strategies. In: Shepherdson DJ, Mellen JD, Hutchins M, editors. Second nature: environmental enrichment for captive animals. Washington, D.C.: Smithsonian Institution Press. p 172-83.

Caro TM, Fitzgibbon CD. 1992. Large carnivores and their prey: the quick and the dead. In Crawley M, editor. Natural enemies: the population biology of predators, parasites and diseases. Boston: Blackwell Scientific Publications. p 117-42.

Curio E. 1976. The ethology of predation. New York: Springer-Verlag. 250 p.

Duckler GL. 1998. An unusual osteological formation in the posterior skulls of captive tigers (Panthera tigris). Zoo Biol 17:135-42.
Fernandes D. 1996. Aspects of the ecology and psychology of feeding and foraging. In: Kleiman D, Allen M, Thompson K, Lumpkin S, editors. Wild mammals in captivity. Chicago: University of Chicago Press. p 372-6.

Frankham R, Hemmer H, Ryder O, Cothran E, Soulé M, Murray N, Snyder M. 1986. Selection in captive populations. Zoo Biol 5:127-38.

Hancocks D. 1980. Bringing nature into the zoo: inexpensive solutions for zoo environments. Int J Study Anim Probl 1:170-7.

Hediger H. 1964. Wild animals in captivity. New York: Dover. 207 p.

Hutchins M, Hancocks D, Crockett C. 1984. Naturalistic solutions to the behavioral problems of captive animals. Der Zoologische Garten 54: 28-42.

Leyhausen P. 1979. Cat behavior: the predatory and social behavior of domestic and wild cats. New York: Garland STPM Press. 340 p.

Lindburg DG. 1988. Improving the feeding of captive felines through application of field data. Zoo Biol 7:211-8.

Lindburg DG. 1998. Enrichment of captive mammals through provisioning. In: Shepherdson DJ, Mellen JD, Hutchins M, editors. Second nature: environmental enrichment for captive animals. Washington, D.C.: Smithsonian Institution Press. p 262-76.

Maple TL, Finlay TW. 1989. Applied primatology in the modern zoo. Zoo Biol Suppl 1:101-16.

Markowitz H. 1982. Behavioral enrichment in the zoo. New York: Van Nostrand Reinhold Co. $210 \mathrm{p}$.

Markowitz H. 1995. Effectiveness of acoustic 'prey': environmental enrichment for a captive African leopard (Panthera pardus). Zoo Biol 14:371-9.

Mason G. 1993. Forms of stereotypic behaviour In: Lawrence AB, Rushen J, editors. Stereotypic animal behaviour: fundamentals and applications to welfare. Wallingford, UK: CAB International. p 7-40.

Mellen JD, Hayes MP, Shepherdson DJ. 1998 Captive environments for small felids. In: Shepherdson DJ, Mellen JD, Hutchins M, editors. 


\section{Carcass Enrichment}

Second nature: environmental enrichment for captive animals. Washington, D.C.: Smithsonian Institution Press. p 184-201.

Newberry RC. 1995. Environmental enrichment: increasing the biological relevance of captive environments. Appl Anim Behav Sci 44:229-43.

Price EO. 1984. Behavioral aspects of animal domestication. Quart Rev Biol 59:1-32.

Rushen J, Lawrence AB, Terlouw EMC. 1993. Forms of stereotypic behaviour. In: Lawrence AB, Rushen J, editors. Stereotypic animal behaviour: fundamentals and applications to welfare. Wallingford, UK: CAB International. p 41-64.

SAS Software Release 6.12, ( 1989-1996 by SAS Institute Inc., Cary, NC.

Seidensticker J, Forthman D. 1998. Evolution, ecology, and enrichment: basic considerations for wild animals in zoos. In: Shepherdson DJ, Mellen JD, Hutchins M, editors. Second nature: environmental enrichment for captive animals. Washington, D.C.: Smithsonian Institution Press. p 15-29.
Seidensticker J, McDougal C. 1993. Tiger predatory behaviour, ecology and conservation. Symp Zool Soc Lond 65:105-25.

Sunquist ME, Sunquist FC. 1989. Ecological constraints on predation by large felids. In: Gittleman JL, editor. Carnivore behavior, ecology, and evolution. Vol. I. Ithaca, NY: Cornell University Press. p 283-301.

Taylor ME. 1989. Locomotor adaptations by carnivores. In: Gittleman JL, editor. Carnivore behavior, ecology, and evolution. Vol. I. Ithaca, NY: Cornell University Press. p 382-409.

Tudge C. 1991. A wild time at the zoo. New Sci 129:26-30.

Tudge C. 1992. Last animals at the zoo: how mass extinction can be stopped. Washington, D.C.: Island Press. 266 p.

Van Valkenburgh B. 1989. Carnivore dental adaptations and diet: a study of trophic diversity within guilds. In: Gittleman JL, editor. Carnivore behavior, ecology, and evolution. Vol. I Ithaca, NY: Cornell University Press. p 410-36. 